Bull. Geol. Soc. Finland 41, 85-91 (1969)

\title{
ON THE EVAPORATION OF SOME ALKALI METALS DURING THE ELECTRON MICROPROBE ANALYSES
}

\author{
JAAKKo Sirvola \\ Geological Survey of Finland, Otaniemi
}

\begin{abstract}
The evaporation of some alkali metals during the electron microprobe analyses was recorded. The results show that both increasing and decreasing alkali intensities can be obtained. The results are given in the form of graphs which show how the evaporation effect depends on the acceleration voltage and on the specimen current.
\end{abstract}

\section{Introduction}

The spot on the specimen surface which is subjected to the electron beam of a microprobe will be heated to some extent depending on the working conditions of the electron optical system and on the heat conductivity of the specimen. The rise of temperature in the sample may be calculated as presented by Reed (1964).

$$
\Delta \mathrm{T}=1.14 \frac{\mathrm{V} \cdot \mathrm{I}}{\mathrm{k} \cdot \mathrm{d}}{ }^{\circ} \mathrm{C} \text {, where }
$$

$\mathrm{V}=$ accelerating voltage in $\mathrm{kV}$

$\mathrm{I}=$ probe current in $\mu \mathrm{A}$

$\mathrm{k}=$ thermal conductivity in cal. $\mathrm{cm}^{-1} \cdot \mathrm{sec}^{-2}$

$\mathrm{d}=$ probe diameter in $\mu$.

The heating may be strong enough to cause volatilization of certain elements, especially of the alkali metals. The bulk composition of the spot will thus be continuously changed during counting. If the rate of volatilization is sufficiently high, the result of the analysis might be measurably erroneous.
Despite the fact that the tendency to volatilize represents a serious problem in microprobe analysis, only two references were found in literature in which the phenomenon was illustrated by quantitative data. Ribbe and Smith (1966) measured the X-ray output of $\mathrm{Na}, \mathrm{Al}$ and $\mathrm{Si}$ on synthetic albite glass and found severe initial reduction in the count rate of sodium with a corresponding increase in that of aluminum and silicon. They state that it is necessary to use very low beam currents $(0.005 \mu \mathrm{A})$ on fine spots $(1-5 \mu)$ to obtain steady readings. Both increasing and decreasing counting rates were obtained in crystalline alkali feldspars. Calcium was found to stabilize the feldspar glasses above the composition $\mathrm{An}_{40}$ and in crystalline plagioclases.

White et al. (1966) presented graphs illustrating the volatilization of potassium from muscovite with acceleration voltages of $30 \mathrm{kV}$ kand $20 \mathrm{kV}$ and spot sizes of $1 \mu$ and $10 \mu$, respectively. They found the potassium volatilization to increase with decreasing spot size and increasing specimen current. For a spot size of $1 \mu$ 
there was a significant potassium loss for a beam current of $0.005 \mu \mathrm{A}$. For a spot size of $100 \mu$ no potassium loss was observed. The potassium loss was always accompanied by an increase in $\mathrm{Si}$ and $\mathrm{Al}$.

In the laboratories of the Geological Survey of Finland a "Geoscan" microprobe of the Cambridge Instrument Co. is currently used for analyzing a wide diversity of materials. In the course of this analytical work, the volatilization effect has been found quite disturbing especially in the quantitative determination of the alkali metals. The standard materials and, in addition, the working conditions of the instrument must be selected in such a way that a constant counting rate is obtained. For that reason, the volatilization effect was subjected to a more systematic study, the results of which are reported in this paper.

\section{Materials and methods}

The volatilization effect was studied on a number of materials summarized in Table 1. This table also indicates the acceleration voltages used on each specimen. The alkali contents of some of the specimens were known on the basis of wet chemical analyses. A specimen current of $40 \mathrm{~m} \mu \mathrm{A}$ and the beam diameter of $2 \mu$ was used throughout. The intensities of the $\mathrm{X}$-ray lines were counted on the same spots during $20 \times 20$ seconds. Immediately after each set of countings the intensities were measured on a nearby fresh spot to ensure constancy of instrumental conditions during a counting series. Because the instrument was provided with two channels, the one channel was used for measuring the X-ray line of an alkali metal and the other channel for measuring the line of either silicon or aluminum etc. In that way, the simultaneous escape of an alkali metal and the enrichment of a non-volatilizing element could be checked.

On some materials which were found to exhibit a strong volatilization effect, the diameter of the
TABle 1

List of materials used for testing the volatilization effect

\begin{tabular}{|c|c|c|c|c|c|}
\hline & \multicolumn{2}{|c|}{$\begin{array}{l}\text { Alkali content } \\
\text { (when known) }\end{array}$} & \multicolumn{3}{|c|}{$\begin{array}{c}\text { Acceleration voltages } \\
\text { used }(+)\end{array}$} \\
\hline & $\mathrm{Na}_{2} \mathrm{O} \%$ & $\mathrm{~K}_{2} \mathrm{O} \%$ & $10 \mathrm{kV}$ & $15 \mathrm{kV}$ & $20 \mathrm{kV}$ \\
\hline Sanidine & 2.60 & 13.58 & + & + & + \\
\hline Anorthoclase & 8.93 & 3.95 & + & + & + \\
\hline $\begin{array}{l}\text { Potassium feld- } \\
\text { spar from rapa- }\end{array}$ & & & & & \\
\hline kivi ${ }^{1} . \ldots \ldots \ldots$ & 一 & - & + & + & + \\
\hline Albite...$\ldots \ldots$ & - & - & + & + & + \\
\hline Oligoclase ...... & 9.46 & 0.22 & + & + & + \\
\hline Leucite ... & 0.23 & 21.45 & + & + & + \\
\hline Pollucite $^{2}$. . & - & - & + & + & + \\
\hline Nepheline ...... & 17.22 & 4.89 & + & + & + \\
\hline Melilite ....... & 3.12 & 一 & + & + & + \\
\hline Microscope slide & 一 & 一 & + & - & - \\
\hline Nepheline glass. & - & 一 & + & + & 一 \\
\hline Melilite glass ... & 3.67 & - & + & + & + \\
\hline Biotite' . . . . . . & 一 & - & + & + & + \\
\hline Muscovite $^{1} . \ldots$ & 一 & 一 & + & + & + \\
\hline Pectolite ...... & - & 一 & + & + & + \\
\hline Aegirine-augite . & 10.29 & 0.28 & - & + & + \\
\hline $\mathrm{NaCl} \ldots \ldots \ldots$ & 一 & 一 & + & + & + \\
\hline Cryolite .... & 一 & - & + & + & + \\
\hline Fluorite ....... & 一 & - & + & + & + \\
\hline Synthetic $\mathrm{MgF}_{2}$. & 一 & 一 & + & + & + \\
\hline
\end{tabular}

1) Several specimens.

2) Acceleration voltage of $30 \mathrm{kV}$ also used.

TABle 2

Instrumental settings used in studying materials with strong volatilization effect

\begin{tabular}{c|c|c|c}
\hline Material & $\begin{array}{c}\text { Acceleration } \\
\text { voltage } \\
\mathrm{kV}\end{array}$ & $\begin{array}{c}\text { Spot size } \\
\mu\end{array}$ & $\begin{array}{c}\text { Specimen } \\
\text { current } \\
\mathrm{m} \mu \mathrm{A}\end{array}$ \\
\hline & 15 & 2 & 320 \\
Leucite ..... & 15 & 2 & 160 \\
& 15 & 2 & 80 \\
& 15 & 2 & 40 \\
& 15 & 2 & 20 \\
& 15 & 2 & 10 \\
& 15 & 2 & 5 \\
& 15 & 10 & 40 \\
& 15 & 2 & 5 \\
& 15 & 40 & 40 \\
& 10 & 2 & 40 \\
& 10 & 100 & 40 \\
& 10 & 40 & 10 \\
& 10 & 2 & 20
\end{tabular}

electron beam and the specimen current was additionally varied in the way summarized in Table 2. 
The specimen surface was vacuum coated with aluminum or copper. The effect of the thickness of this coating upon the volatilization was studied on only a few specimens If the thickness of the coating was increased it was found to prevent the volatilization somewhat. On the other hand, the increasing thickness of the coating depressed the intensity of the lines of the more light elements rather rapidly.

\section{Results}

The intensities of the $\mathrm{X}$-ray lines were measured using counting times of 20 seconds. After each period the number of counts obtained was registered with the printer after which a new counting period was started. The time needed by the printer for registering the counts of a period was approximately $3 \frac{1}{2}$ seconds. The number of counts obtained during the periods $t_{1}--t_{n}$ was $c_{1}--c_{n}$. Following the manner of presentation used by White et al. (1966) the counting results will be summarized in the form of the graphs in Figs. 1-6. In these figures the abscissa indicates the successive number of a counting period. The ordinate indicates the relative intensity, i.e., the number of counts during that period divided by the number of counts obtained during the first period $\left(c_{n} / c_{1}\right)$. This way of presentation has the advantage of enabling a mutual comparison of the results for different minerals and for different elements.

Cryolite, $\mathrm{Na}_{3} \mathrm{Al} \mathrm{F}_{6}$ (Fig. 1). The intensities of both sodium and aluminum lines increase during counting. Repeated measurements using acceleration voltages of $10 \mathrm{kV}$ and $20 \mathrm{kV}$, respectively, showed no difference in the rate of increase. The figure reproduces only the results obtained on $10 \mathrm{kV}$. For both metals the intensity increase is more rapid for a beam diameter of $40 \mu$ than for that of $2 \mu$. Fluorine could not be measured with the microprobe available for the study. It seems, however, that the cryolite

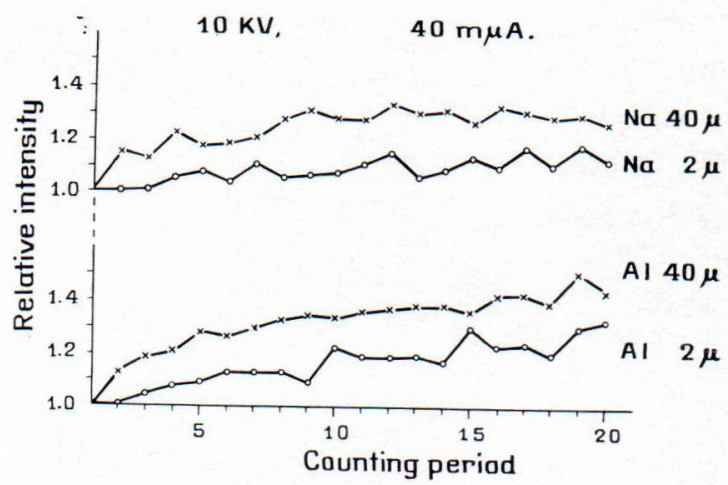

Fig. 1. Relative intensity of $\mathrm{Al}$ and $\mathrm{Na}$ on cryolite. Spot diameter $2 \mu$ and $40 \mu$, respectively.

structure decomposes to some extent when subjected to the electron beam and that the fluorine is partially volatilized. On synthetic $\mathrm{MgF}_{2}$ and on natural fluorite no changes in the intensities of the magnesium or calcium lines were detected indicating that the structures of these materials are not affected by the electron beam.

The following materials did not disclose any notable changes in the intensities of the sodium or potassium lines: $\mathrm{NaCl}$, crystalline melilite, fused natural melilite (melilite glass), aegirineaugite and biotite (phlogopite).

Leucite displays a severe reduction of the count rate indicating a strong volatilization of potassium. With constant acceleration voltage the potassium loss increases with increasing specimen current (Fig. 2 A). Using an acceleration voltage of $15 \mathrm{kV}$ and a specimen current of not more than $20 \mathrm{~m} \mu \mathrm{A}$, the count rate remains unchanged for one minute. For higher specimen currents the count rate already decreases strongly during the first counting period. With constant specimen current the potassium loss increases with decreasing acceleration voltage (Fig. 2 B, bottom). This remarkable behavior will be more pronounced after longer counting times. The diffusion of potassium to the spot under the beam is apparently too slow to compensate for the amount of potassium volatilized. For a higher acceleration voltage the area around the 

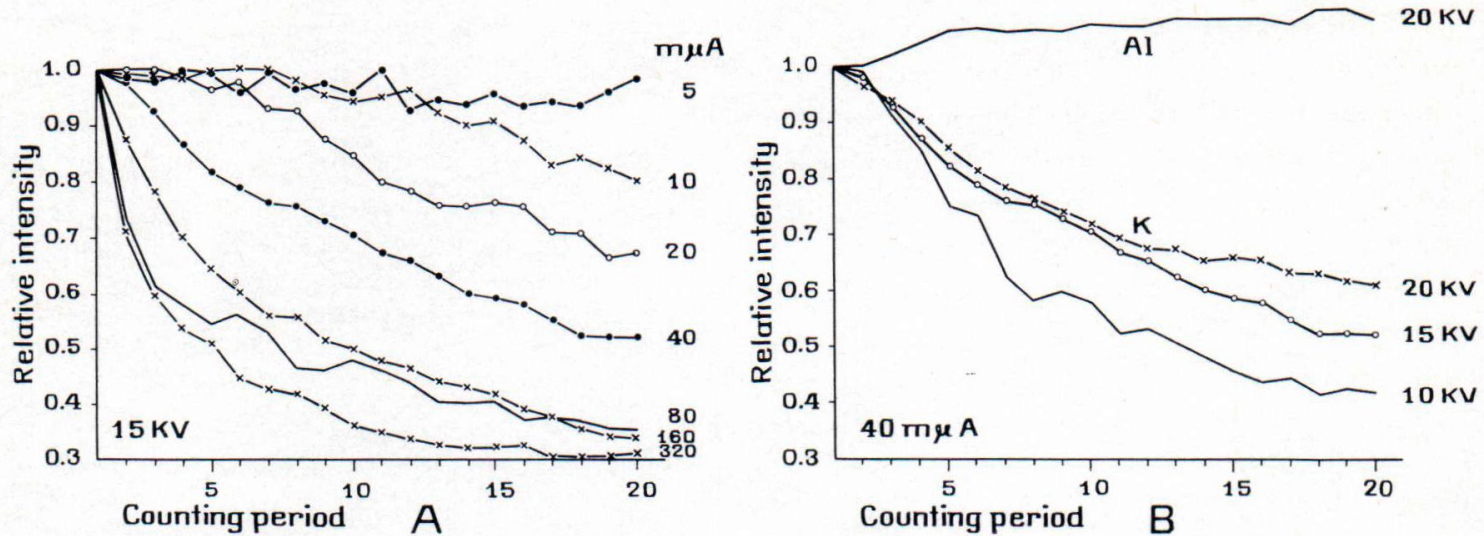

Fig. 2. Relative intensity of $\mathrm{K}$ and $\mathrm{Al}$ on leucite. A. Potassium loss as a function of specimen current. B. Potassium loss as a function of acceleration voltage (bottom); aluminium gain (top).

spot will be heated more strongly. The rate of diffusion increases and the net loss of potassium will remain less significant. The potassium loss is accompanied by an increase of the $\mathrm{Al}$ intensity (Fig. 2 B, top). It is concluded that leucite is not suitable as a standard material in microprobe analysis.

On crystalline nepheline and on fused natural nepheline (nepheline glass) $\mathrm{K}$ and $\mathrm{Na}$ were measured simultaneously. As is illustrated in Fig. 3, sodium is volatilized from both materials more rapidly than potassium. On the crystalline nepheline the potassium intensity remains constant for acceleration voltages of $15 \mathrm{kV}$ and $20 \mathrm{kV}$. For $10 \mathrm{kV}$, however, the potassium loss becomes significant. The Al intensity increases slightly during counting. On the other hand, the loss of both sodium and potassium from the nepheline glass is rapid. For example, during the first counting period the sodium intensity is reduced to one half of the initial intensity.

The alkali loss from an ordinary glass plate used for making thin sections of rocks (using $10 \mathrm{kV}, 40 \mathrm{~m} \mu \mathrm{A}, 2 \mu$ ) is virtually identical with the alkali loss from the fused nepheline glass $(15 \mathrm{kV}, 40 \mathrm{~m} \mu \mathrm{A}, 2 \mu)$. The sodium and potassium intensities on the microscope slide remain stable for $10 \mathrm{kV}$ if the specimen current is retained at $40 \mathrm{~m} \mu \mathrm{A}$ and the beam diameter at $100 \mu$ or $10 \mathrm{~m} \mu \mathrm{A}$ and $20 \mu$, respectively. No increasing alkali intensities were found.

The alkali intensities on feldspars is illustrated in Fig. 4. On the alkali feldspars the potassium intensity often exhibits a slight initial increase or tends to remain stable whereas the sodium intensity tends to decrease more readily. The amount of the alkali loss seems to vary with the type of feldspar. On sanidine (Fig. $4 \mathrm{~A}$ ) the sodium intensity shows a strong initial decrease accompanied by a slight increase in potassium intensity. Later, both intensities decrease considerably, that of sodium more strongly.

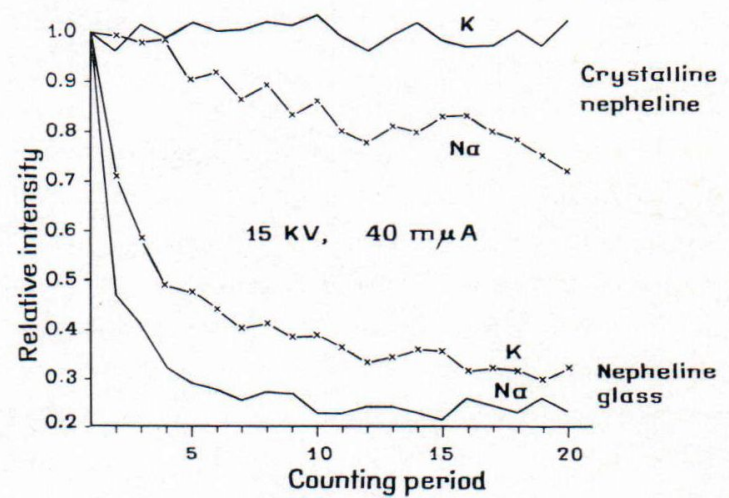

Fig. 3. Relative intensity of $\mathrm{K}$ and $\mathrm{Na}$ on crystalline nepheline (top) and on nepheline glass (bottom). 

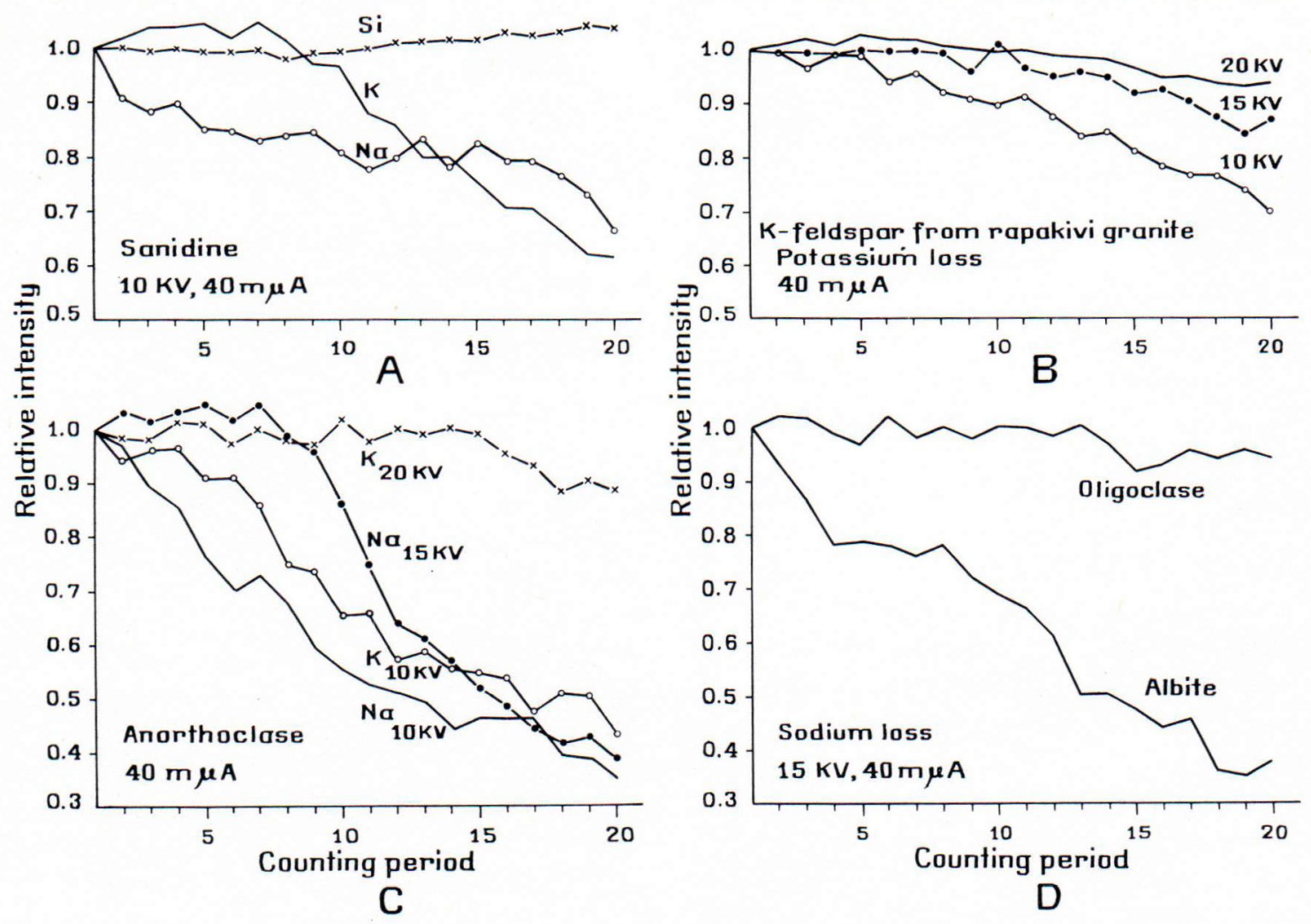

Fig. 4. Relative intensities of $\mathrm{K}$ and $\mathrm{Na}$ on feldspars.

After an initial stability the silicon intensity starts increasing. For higher acceleration voltages the alkali intensities remain stable for a longer time (not shown in the figure). The potassium intensity obtained from a potassium feldspar of the rapakivi granite (Fig. 4 B) displays a relationship between acceleration voltage and potassium loss which is similar to that found for leucite. From anorthoclase (Fig. 4 C) the relative volatilization of the alkalies depends on the acceleration voltage. For $10 \mathrm{kV}$ the volatilization is such that the ratio of potassium to sodium remains unchanged. For $20 \mathrm{kV}$ the sodium intensity increases initially and, later, drops suddenly whereas the potassium intensity remains more stable. Fig. $4 \mathrm{D}$ illustrates the difference in sodium loss between albite and oligoclase. In albite the sodium loss is strong. In oligoclase the sodium intensity remains constant. The calcium content of the oligoclase probably makes the structure persistent against the electron beam.

\section{TABLE 3}

The volatilization effect of potassium and sodium in nepheline, sanidine, anorthoclase and leucite

\begin{tabular}{|c|c|c|c|c|c|c|}
\hline & \multicolumn{3}{|c|}{$\begin{array}{l}\text { relative potassium loss } \\
20 \mathrm{kV} 15 \mathrm{kV} 10 \mathrm{kV}\end{array}$} & \multicolumn{3}{|c|}{$\begin{array}{l}\text { relative sodium loss } \\
20 \mathrm{kV} 15 \mathrm{kV} 10 \mathrm{kV}\end{array}$} \\
\hline ephel & 1.0 & 1.0 & 0.84 & 0.90 & 0.70 & 0.65 \\
\hline sanidine ..... & 1.0 & 0.98 & .65 & .94 & .92 & .67 \\
\hline anorthoclase . & 0.88 & .73 & .42 & .43 & .39 & .34 \\
\hline leucite & .60 & .52 & .41 & - & - & - \\
\hline
\end{tabular}

Table 3. summarizes the magnitude of the relative potassium and sodium losses of some minerals after a $20 \times 20$ seconds measuring period with different accelerating voltages (with specimen current of $40 \mathrm{~m} \mu \mathrm{A}$ and $2 \mu$ spot). The 
table shows that the evaporation effect is more intense with lower beam loadings, a fact which can readily be seen in the graphs.

Fig. 5 illustrates the potassium loss from two specimens of muscovite. Using a small diameter of the electron beam the potassium loss increases with decreasing acceleration voltage (not shown in the figure).

Fig. 6 illustrates the sodium loss from pollucite and from pectolite. For pollucite the sodium loss decreases with decreasing acceleration voltage. The figure shows the loss obtained for $20 \mathrm{kV}$. For $15 \mathrm{kV}$ the intensity starts decreasing after $14 \times 20$ seconds and for $10 \mathrm{kV}$ no sodium loss was detected. As will be shown in Fig. 7, no cesium loss was observed, not even on using an acceleration voltage of $30 \mathrm{kV}$ and a specimen current of $100 \mathrm{~m} \mu \mathrm{A}$. The sodium loss from pectolite is clear for all acceleration voltages used (Table 1). No volatilization effect of calcium was observed on wollastonite.

Fig. 7 summarizes the alkali loss from a few minerals. The relative intensities are presented in cumulative graphs as functions of the counting times. If no reduction of count rate occurs, then the graph will be a straight line with a slope of $45^{\circ}$. Such a case in the figure is represented by the Cs intensity on pollucite. If the count rate increases with time, then the curve will be above that straight line, as is the $\mathrm{Na}$ intensity on cryolite. If the count rate exhibits a decrease with time, then the curve will lie below the straight line (for example $\mathrm{K}$ on leucite).

\section{Conclusions}

From the data presented the following general conclusions may be drawn:

1. The contents of sodium and potassium in the spot subjected to the electron beam can either increase or decrease during counting. Simultaneously, the contents of the other elements will increase. Fluorine represents an excep-

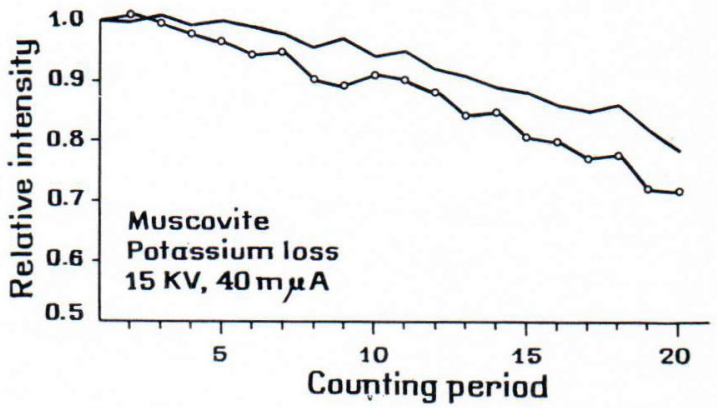

Fig. 5. Relative intensity of $\mathrm{K}$ on muscovite. Upper curve: muscovite from pegmatite, Kaatiala, Finland. Lower curve muscovite from trondhjemite, Virtasalmi, Finland.

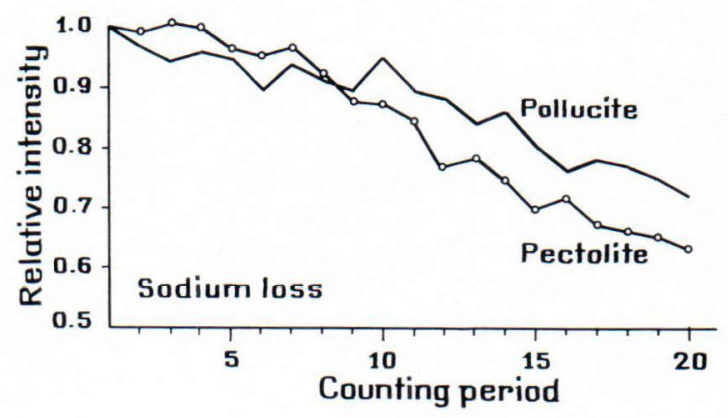

Fig. 6. Relative intensity of $\mathrm{Na}$ on pollucite $(20 \mathrm{kV}, 60$ $\mathrm{m} \mu \mathrm{A})$ and on pectolite $(10 \mathrm{kV}), 40 \mathrm{~m} \mu \mathrm{A})$.

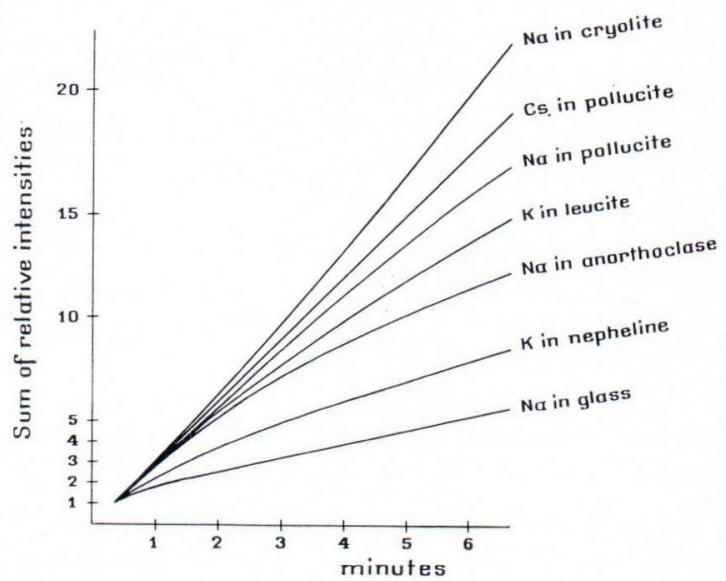

Fig. 7. Cumulative presentation of the alkali losses from a few minerals. 
tion to this rule. From the cryolite structure fluorine will be volatilized.

2. Sodium is generally volatilized more easily than potassium. This rule is also valid for the synthetic materials studied. Cesium shows no tendency to volatilize.

3. The rate of volatilization of sodium and potassium depends on the acceleration voltage and on the specimen current. The rate of volatilization increases with decreasing acceleration voltage and increasing specimen current.

4. The volatilization also depends on the diameter of the electron beam. An increase of the beam diameter depresses the volatilization, but, of course, decreases the resolution. An exception is offered by cryolite in which an increasing beam diameter causes an increasing gain of $\mathrm{Na}$ and $\mathrm{Al}$.

5. The feldspar $\left(<A n_{40}\right)$ and feldspathoid glasses and crystalline feldspathoids are not suitable for use as standard materials during spot analysis. The volatilization of $\mathrm{Na}$ and $\mathrm{Ka}$ is too strong.

6. The presence of $\mathrm{Ca}, \mathrm{Mg}$ and $\mathrm{Fe}$ stabilizes the crystalline minerals and glasses studied. The $\mathrm{Na}$ and $\mathrm{K}$ intensities remain constant.

If the evaporation from the sample is expected to be considerable, then a large spot, a low specimen current and a high acceleration voltage should be used. However, a large spot cannot be used on a heterogeneous specimen with inclusions, exsolution lamellae etc. A low specimen current results in a low intensity of the $\mathrm{X}$-ray line to be measured and makes it necessary to expand the measuring time with a correspondingly advanced evaporation. A certain compromise between the requirements mentioned must be selected. A high beam loading would depress the alkali loss at least in some specimens. The absorption effect would also be decreased, but, due to increased background radiation, the limit of detection would rise especially for the light element. A specimen scanning during counting would largely eliminate the evaporation effect, but would require large homogeneous samples and is mostly not possible to use.

If evaporation cannot be avoided, its effect can easily be measured by using the cumulative curves of the type in Fig. 7. Using such a graph the correction needed to calculate the true intensity is represented by the difference between the intensity curve actually measured and the straight line presented by the Cs intensity in the figure. This method of making the correction is analogous to the way of determining the dead time correction of a proportional counter.

Acknowledgments - The author wishes to express his sincere thanks to Miss Karin Dahl for drawing the graphs and to Mr. Boris Saltikoff, M.A., for assistance in the laboratory.

\section{REFERENCES}

REED, S. J. B.: Thesis, Department of Mineralogy and Petrology, University of Cambridge, England. 1964. RibBe, P. H. and Smith, J. V.: X-ray-emission microanalysis of rock-forming minerals. IV. Plagioclase feldspars. J. of Geology. Vol. 74, No. 2, pp. 217-233, 1966.
White, E. W., Denny, P. J. and Irving, S. M.: Quantitative microprobe analysis of microcrystalline powders. "The electron microprobe" edited by T. D. McKinley, pp. 791—804, 1966.

Manuscript received, September 10, 1968. 